\title{
Global burden of antenatal depression and its association with adverse birth outcomes: an umbrella review
}

\author{
Abel Fekadu Dadi ${ }^{1} 2^{*} \mathbb{D}$, Emma R. Miller ${ }^{1}$, Telake Azale Bisetegn ${ }^{3}$ and Lillian Mwanri ${ }^{1}$
}

\begin{abstract}
Background: Women of childbearing age are at high risk of developing depression and antenatal depression is one of the most common mood disorders. Antenatal depression is also associated with a number of poor maternal and infant outcomes, however, there remains a lack of focus on mental issues in antenatal care, particularly in lower income countries. This systematic review of reviews provides useful evidence regarding the burden of antenatal depression which may provide guidance for health policy development and planning.

Methods: We searched CINAHL(EBSCO), MEDLINE (via Ovid), PsycINFO, Emcare, PubMed, Psychiatry Online, and Scopus databases for systematic reviews that based on observational studies that were published in between January 1st, 2007 and August 31st, 2018. We used the Assessment of Multiple Systematic Reviews (AMSTAR) checklist scores to assess the quality of the included reviews. We applied vote counting and narrative review to summarize the prevalence of antenatal depression and its associated factors, while statistical pooling was conducted for estimating the association of antenatal depression with low birth weight and preterm birth. This systematic review of reviews was registered on PROSPERO with protocol number CRD42018116267.
\end{abstract}

Results: We have included ten reviews (306 studies with 877,246 participants) on antenatal depression prevalence and six reviews (39 studies with 75,451 participants) conducted to identify the effect of antenatal depression on preterm and low birth weight. Globally, we found that antenatal depression prevalence ranged from 15 to $65 \%$. We identified the following prominent risk factors based on their degree of influence: Current or previous exposure to different forms of abuse and violence (six reviews and 73 studies); lack of social and/or partner support (four reviews and 47 studies); personal or family history of any common mental disorder (three reviews and 34 studies). The risk of low birth weight and preterm birth was $1.49\left(95 \% \mathrm{Cl}: 1.32,1.68 ; P^{2}=0.0 \%\right)$ and 1.40 (95\%Cl: 1.16, 1.69; $\left.P^{2}=35.2 \%\right)$ times higher among infants born from depressed mothers.

Conclusions: Globally, antenatal depression prevalence was high and could be considered a common mental disorder during pregnancy. Though the association between antenatal depression and adverse birth outcomes appeared to be modest, its absolute impact would be significant in lower-income countries with a high prevalence of antenatal depression and poor access to quality mental health services.

Keywords: Antenatal depression, Adverse birth outcomes, Review of reviews

\footnotetext{
* Correspondence: Fekten@yahoo.com

${ }^{1}$ College of Medicine and Public Health, Flinders University, Health Sciences

Building, Sturt Road, Bedford Park, Adelaide, SA 5001, Australia

2Department of Epidemiology and Biostatistics, Institute of Public Health,

College of Medicine and Health Sciences, University of Gondar, Gondar,

Ethiopia

Full list of author information is available at the end of the article
}

(c) The Author(s). 2020 Open Access This article is distributed under the terms of the Creative Commons Attribution 4.0 International License (http://creativecommons.org/licenses/by/4.0/), which permits unrestricted use, distribution, and reproduction in any medium, provided you give appropriate credit to the original author(s) and the source, provide a link to the Creative Commons license, and indicate if changes were made. The Creative Commons Public Domain Dedication waiver (http://creativecommons.org/publicdomain/zero/1.0/) applies to the data made available in this article, unless otherwise stated. 


\section{Background}

The fifth edition of the Diagnostic and Statistical Manual of Mental Disorder (DSM-IV) defines antenatal depression as Major Depressive Episode (MDD), which mostly associated with environmental and genetic factors [1]. Childbearing age for females is the time of highest risk for developing depression and antenatal depression is one of the least investigated and under-treated disorders $[2,3]$. Antenatal depression is thought to be exacerbated by a high rate of peptide and steroid hormone fluctuation occurring during pregnancy and childbearing age [4]. The prevalence of antenatal depression ranges from 7 to $20 \%$ at each trimester of pregnancy $[5,6]$ and longitudinal studies suggest that antenatal depression symptoms tend to persist or re-occur in subsequent pregnancies $[7,8]$.

Antenatal depression affects maternal quality of life and is a major cause of disease burden in both developed and developing countries; it is responsible for an estimated $6.2 \%$ of life years lived with disability [9-11]. Antenatal depression also has a high economic burden related to health service utilization estimated to reach up to 8.1 billion pounds in the United Kingdom [12] in addition to those costs associated with poorer human capital [13].

At an individual level, the risk of low birth weight, preterm birth, intrauterine growth restriction, and pregnancy complications [2, 14-20] are known to be higher in association with antenatal depression. In addition, antenatal depression has been linked to infant developmental, emotional and attachment problems, poor academic performance, malnutrition, respiratory disorders and a higher risk of the infant developing mental health disorders in later life [21-27]. Depression during pregnancy can affect maternal health seeking behavior, adherence with medical and psychological interventions and increased risk behaviors, such as that substance use and misuse [28, 29].

Reducing infant and child mortality is the primary target set for the health sector in the Sustainable Development Goals [30, 31]. The Sustainable Development Goals (SDGs) is a United Nations global initiative to end poverty, protect the planet and to ensure peace and prosperity to all global citizens by 2030 in which all the member states are pledged to achieve. Adverse birth outcomes, such as low birth weight and preterm birth, are the leading cause of infant and childhood morbidity, mortality, and neurodevelopmental impairment [18, 32 , 33]. Despite the burden of preterm and low birth weight remaining high, the related risk factor of maternal mental health has not yet been a focus for prevention and control strategies set by low- and middle-income countries where $60 \%$ of births born are preterm and low weight [32-36].
The lack of policy attention on mental health problems in women of reproductive age, and the correspondingly limited number of interventions aimed at alleviating the problem in many countries might be due to a lack of comprehensive evidence. In considering published systematic reviews, decision makers could potentially be faced with a range of conclusions, and reviews that differ with respect to quality and scope. Conducting a systematic review of reviews in a logical and appropriate manner would allow for the comparison, contrasting, and production of evidence that would help policy makers and clinicians for planning appropriate and timely interventions [37] . As such, our current systematic review of reviews would have a potential usefulness for country health ministries that have suffered from inconsistent conclusions about the problem magnitude and who were unable to set intervention modalities.

\section{Methods \\ Overview of a systematic review of reviews}

A systematic review of systematic reviews, also known as an 'umbrella review' is a synthesis that includes only other systematic reviews, which represent the highest form of evidence. This approach aims to provide a single comprehensive source of evidence and in recent years has been increasingly used to guide policymakers and those developing intervention modalities, clinical guidelines, and in the evaluation of health care interventions $[38,39]$. As with other reviews, a systematic review of reviews, follows a systematic approach in searching the literature, appraisal, quality assessment, synthesis and reporting of the compiled results [37, 40, 41].

\section{Search strategy and inclusion criteria for systematic reviews}

We searched CINAHL(EBSCO), MEDLINE (via Ovid), PsycINFO, Emcare, PubMed, Psychiatry Online, and Scopus databases for systematic reviews based on observational studies. To include the most up to date reviews on the topic, only those published between January 1st, 2007 and August 31st, 2018 were considered. The primary outcomes of this review of reviews was the burden of antenatal depression and any associated adverse birth outcomes - specifically, low birth weight, preterm birth, and still birth.

\section{Outcome measures}

systematic reviews that clearly measured and reported the following outcomes were included: [1] depression during pregnancy measured using a validated screening or diagnostic tool [2]; objectively measured birth weight and low birth weight was classified as a weight less than $2500 \mathrm{~g}$ [3]; gestation and age measured using a Last Menstrual Cycle (LMP) or supported by an ultrasound 
and preterm birth defined as a birth before 37 completed weeks of gestation; and [4] stillbirth defined as a fetal death after 20 completed weeks of gestation and weighing at least $500 \mathrm{~g}$, intrauterine fetal death prior to the onset of labor, or intrauterine fetal death during labor and delivery.

\section{Example of search strategy for antenatal depression in PsycINFO via Ovid}

( ( antenatal depression.mp. [mp = title, abstract, heading word, table of contents, key concepts, original title, tests \& measures]) OR (depression during pregnancy.mp. [ $\mathrm{mp}=$ title, abstract, heading word, table of contents, key concepts, original title, tests \& measures]))) AND (((systematic review.mp. [ $\mathrm{mp}=$ title, abstract, heading word, table of contents, key concepts, original title, tests \& measures]) OR (meta-analysis.mp. [mp = title, abstract, heading word, table of contents, key concepts, original title, tests \& measures] OR (review.mp. [mp = title, abstract, heading word, table of contents, key concepts, original title, tests \& measures])))

\section{Inclusion}

reviews fulfilling the following criteria were included: [1] published with systematic review/meta-analysis in their title [2]; antenatal depression and its effect on birth outcomes was the primary objective [3]; systematically searched for primary studies in at least two medical literature data bases [3]; included at least one primary study that aimed to investigate antenatal depression and/or its effect on birth outcomes [5]; quality of included primary studies was assessed and considered in the analysis; and [6] if estimates in the primary reviews were meta-analyzed; the methodology, the model, publication bias, and heterogeneity issues were addressed and clearly reported.

\section{Exclusion}

reviews were excluded if they included primary studies that screened depression in high risk populations (obese, overweight, diabetes, mothers with poor obstetric history, unintended pregnancy, primi-mothers) and reviews for which it was not possible to retrieve the full article.

\section{Risk of bias and data extraction}

All reviews meeting the inclusion criteria were imported to an Endnote database. After duplicates were removed, titles and abstracts were assessed for eligibility prior to full text review. Reviews fulfilling the inclusion criteria through full text review were then assessed for their quality. Quality was assessed using Assessment of Multiple Systematic Reviews (AMSTAR) checklist scores. The checklist contains 11 indicators that are used to derive an overall score assessed as high quality (score $>=8$ ), medium quality (score 4-7), and low quality (score $<=3$ ). Two reviewers (AF \& TA) independently assessed the quality of each review with an internal consistency of $98 \%$ and agreement was reached by discussion for the remaining $2 \%$. The data were extracted and tabulated: author and publication year; geographic coverage of the review; data base searched; depression assessment tool used; number of primary studies included; if meta-analyses were conducted, the pooled number of participants $(\mathrm{N})$; main findings; and AMSTAR score.

\section{Strategy for data synthesis}

The data synthesis was undertaken independently for each outcome of interest. Vote counting and narrative review were used to summarize and present the main findings for antenatal depression and associated factors. Statistical pooling (meta-analysis) was conducted for quantifying the effect of antenatal depression on low birth weight and preterm birth. A funnel plot and Egger's regression test was used to check for potential publication bias. Where minor publication bias was identified, Tweedie's and Duval's trim and fill analysis was used as an adjustment. Heterogeneity among the studies was tested using the Higgins method, in which $I^{2}$ statistics were calculated and compared with the standard. The data were imported and analyzed using Stata 14 software (StataCorp. 2015. Stata Statistical Software: Release 14. College Station, TX: StataCorp LP). This systematic review of reviews was registered on PROSPERO with protocol number CRD42018116267.

\section{Results}

Search

We identified 230 items related to antenatal depression and 35 items related to the association between antenatal depression and birth outcomes. After duplicate removal and abstract review, 19 reviews conducted on antenatal depression prevalence and 14 reviews conducted on antenatal depression and adverse birth outcomes underwent a full text review. Seventeen reviews were excluded for the following reasons, the review/s: was a compiled report [27]; focused on perinatal depression [3, 42-44]; had non-relevant study objectives [23, 24, 45, 46]; were not systematic reviews (e.g. overviews, literature reviews or critical literature reviews) [25, 26, 47]; included primary studies conducted on high risk population $[48,49]$, searched only one database [50]; focused on exposures or outcomes that differed substantially from the main objectives of the current study [51] or; had no available full text [52].

The remaining ten reviews (collectively consisting of 306 primary studies and 877,246 study participants) on antenatal depression prevalence $[6,46,53-60]$ and six 
reviews (collectively consisting of 39 primary studies and 75,451 study participants) on the association between antenatal depression association and adverse birth outcomes [14-17, 61, 62] were included in the current review of reviews after assessed for quality. (Fig. 1).

\section{Antenatal depression prevalence and associated factors Characteristics of included reviews}

All included reviews were published from 2010 onwards and included only primary studies that were published from 1968 to 2017. The number of primary studies included in each of the reviews ranged from seven (with 2161 participants) to 97 (with 1,541,303 participants). Seven reviews included a majority of studies from developed countries, two reviews included only primary studies from low and middle-income countries, and one review included primary studies from only Asian countries. The predominant screening tool for measuring antenatal depression was the Edinburgh Postnatal Depression Scale (EPDS) [63], which was used by 101 primary studies across all of the reviews. PubMed/MEDLINE, Psych INFO, CINHAL and Scopus databases were the most cited data bases for searching primary studies. Four reviews reported a pooled prevalence of antenatal depression and all reviews reported risk factors associated with antenatal depression (see Table 1). Only four reviews assessed the quality of included primary studies using a standard quality assessment tool and [8] respectively, two and eight reviews fulfilled a criterion for upper and middle quality scores on AMSTAR (see Table 2).

\section{Findings}

As is presented in Table 1, antenatal depression prevalence ranged from 15 to 65\% [54] and, among reviews reporting a pooled prevalence, antenatal depression prevalence in low and middle-income countries was higher than in high-income countries.

Psychosocial factors were the most common risk factors for antenatal depression identified across all reviews. Current or previous exposure to different forms of abuse and violence was associated with antenatal depression in six reviews of a total of 73 primary studies (collectively including over 290,000 pregnant mothers). Lack of social and partner support was the next most commonly associated risk factor for antenatal depression as reported in four systematic reviews, encompassing 47 primary studies (around 226,000 study participants). Personal or family history of any common mental disorder was the third most reported risk factor, reported in three reviews and 34 primary studies (involving around 177,000 study participants in total).

Other variables commonly associated with antenatal depression were related to maternal obstetric and economic factors. Unplanned or unwanted pregnancy significantly increased the risk of antenatal depression and the risk was much higher in premature or nulliparous mothers in three reviews involving 36 primary studies (more than 70,296 participants). Lower economic status or financial difficulty also increased the risk of antenatal depression in three reviews of 32 primary studies (more than 20,000 pregnant mothers). Having a history of poor obstetric outcomes, such as past

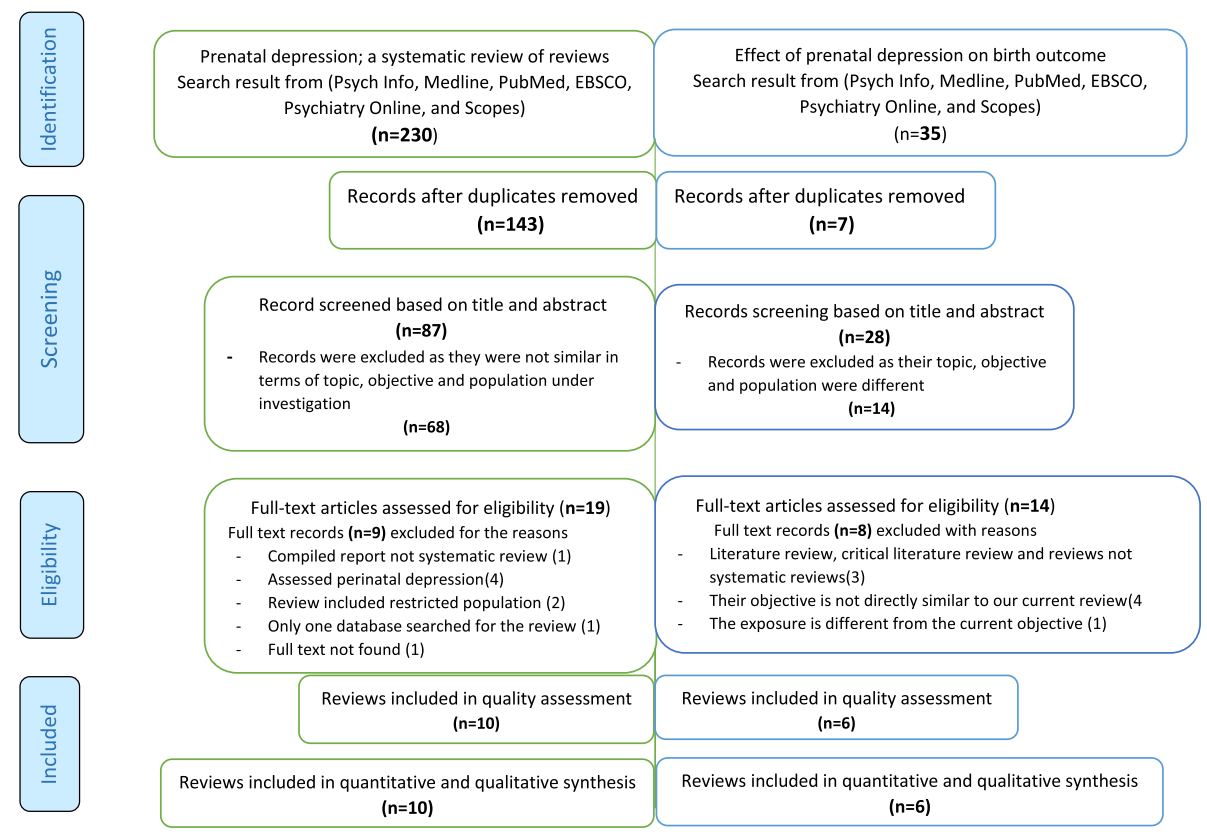

Fig. 1 PRISMA diagram for systematic review of reviews conducted on antenatal depression and its effect on adverse birth outcomes 


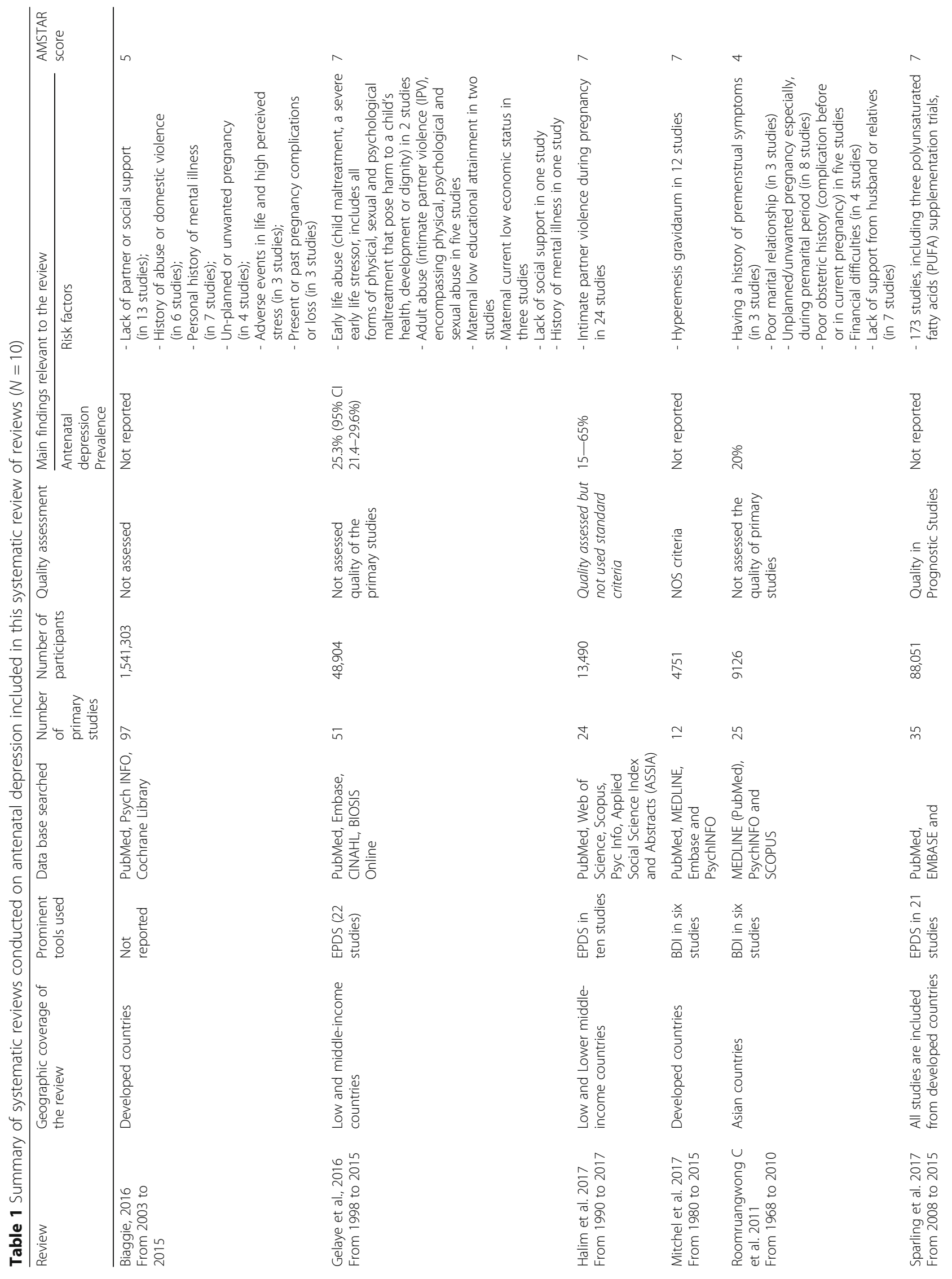




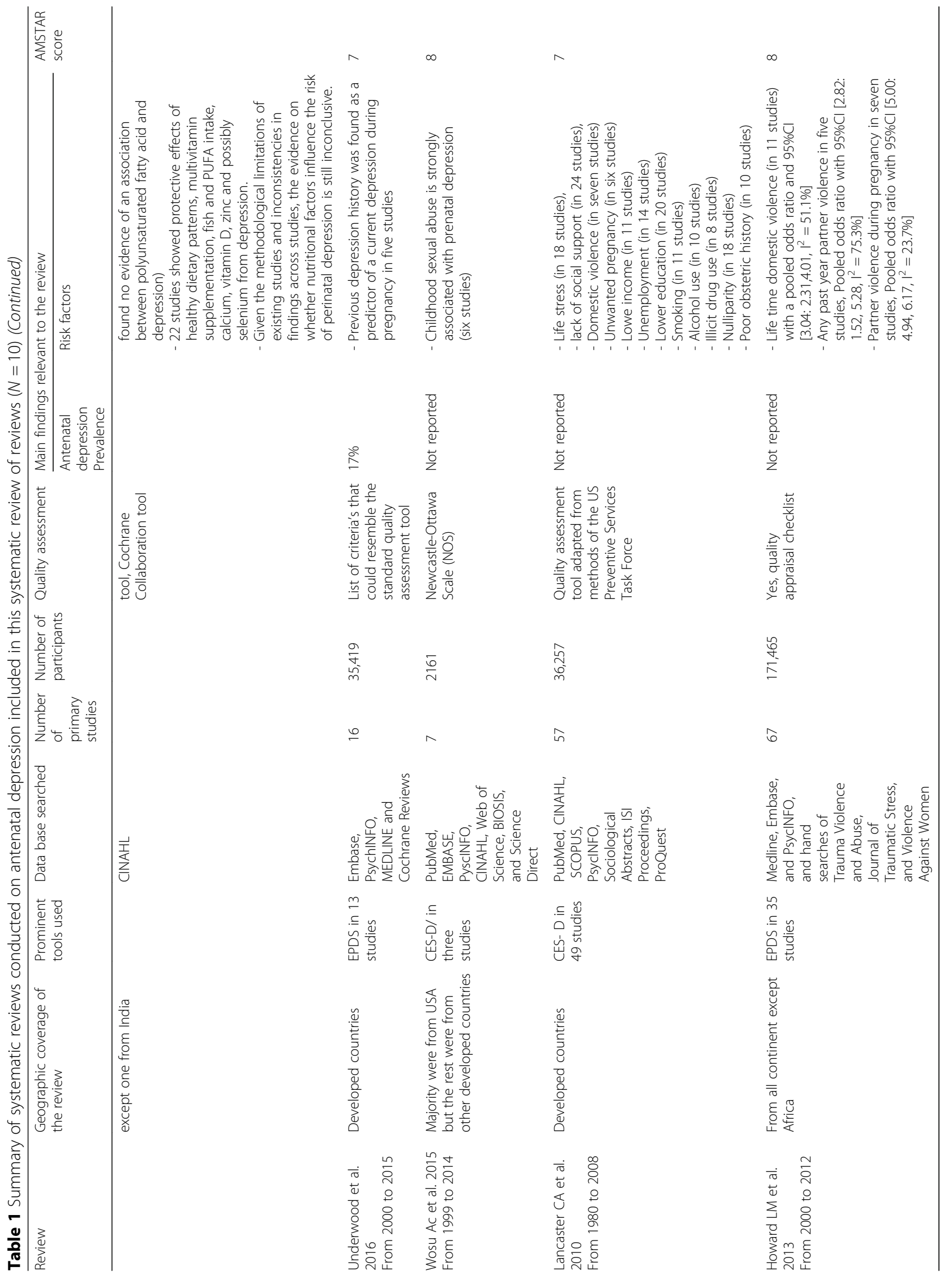


Table 2 Summary of risk factors associated with antenatal depression $(N=10)$

\begin{tabular}{|c|c|c|c|}
\hline Risk factors & $\begin{array}{l}\text { Number of reviews in which } \\
\text { the risk factor was reported }\end{array}$ & $\begin{array}{l}\text { Number of primary studies in } \\
\text { which the factor was reported }\end{array}$ & $\begin{array}{l}\text { Total } \\
\text { participants }\end{array}$ \\
\hline $\begin{array}{l}\text { History of abuse (childhood or current sexual, physical or psychological) } \\
\text { or domestic violence or intimate partner violence }\end{array}$ & 6 & 73 & 293,621 \\
\hline Lack of partner or of social support and poor marital relationship & 4 & 47 & 226,078 \\
\hline Personal or family history of any mental disorder or stress & 3 & 34 & 177,014 \\
\hline $\begin{array}{l}\text { Un-planned or unwanted pregnancy specially during premarital condition } \\
\text { or nullparity }\end{array}$ & 3 & 36 & 70,296 \\
\hline $\begin{array}{l}\text { History of poor obstetric condition like current or past pregnancy } \\
\text { complications such as hyperemesis gravidurum, adverse birth outcomes } \\
\text { (low birth weight, preterm, still birth or infant lose after delivery), had } \\
\text { cesarean section delivery }\end{array}$ & 4 & 33 & 56,916 \\
\hline $\begin{array}{l}\text { Maternal low economic status or unemployment condition or financial } \\
\text { difficulties }\end{array}$ & 3 & 32 & 20,239 \\
\hline $\begin{array}{l}\text { Maternal poor behavioral condition or practices like smoking, alcohol use, } \\
\text { illicit drug use) }\end{array}$ & 1 & 29 & 18,444 \\
\hline \multirow[t]{2}{*}{ Maternal low educational status } & 2 & 22 & 14,638 \\
\hline & 10 reviews & 306 primary studies & $\begin{array}{l}877,246 \\
\text { participants }\end{array}$ \\
\hline
\end{tabular}

pregnancy complications (hyperemesis gravidarum, cesarean section, hypertension, diabetes mellitus), adverse birth outcomes (low birth weight, preterm birth, stillbirth, abortion), and infant loss after birth was also associated with increased risk of antenatal depression in four reviews of 33 primary studies (around 57,000 pregnant mothers).

Education level and lifestyle factors were also associated with an increased risk of antenatal depression (see Table 2). Pregnant mothers with a history of smoking, alcohol and illicit drug use were significantly associated with depression in one review of 29 primary studies (approximately 18,000 participants). In two reviews (of 22 primary studies and more than 14,000 mothers,) low educational status was associated with increased risk the development of antenatal depression. One review conducted to test the role of diet and nutritional supplementation on antenatal depression reported inconclusive findings [59]. (Table 3).

\section{Association of antenatal depression with adverse birth outcomes Characteristics of included reviews}

We identified six reviews that investigated the effect of antenatal depression on birth outcomes, with preterm birth and low birth weight as the main adverse outcomes reported. The systematic reviews were published from 2010 onwards and included primary studies that were published from 1977 to 2015 that were conducted in developed countries. The Center for Epidemiological Depression Scale (CED-S) [64] was the most commonly used screening tool in the reviewed primary studies (used by 52 studies), among which 25 primary studies investigated the association between antenatal depression and low birth weight and 39 investigated the association between antenatal depression and preterm birth. Three of the six reviews included a meta-analysis (see Table 4). Four reviews fulfilled the higher quality criteria of the AMSTAR assessment and the remainder were scored in the mid-range (see Table 5).

\section{Findings}

Four of the five reviews investigating low birth weight reported an increased risk $[14,15,17,61]$ among mothers with antenatal depression and one review reported no association [16]. In regard to preterm birth, four of the five reviews focusing on this outcome reported that antenatal depression increased the risk [15, $16,61,62]$ and one reported non-conclusive findings [17]. (Table 6).

By pooling the estimates of three reviews (see Table 3 ), we estimated that the risk of preterm birth and low birth weight was 1.49 (95\%CI: 1.32, 1.68; $\left.I^{2}=0.0 \%\right)$ and 1.39 (95\%CI: $\left.1.22,1.58 ; I^{2}=35.2 \%\right)$ times higher among pregnant mothers with antenatal depression, respectively. Our test of publication bias confirmed no evidence of missing studies, and the results of our sensitivity analysis indicated that no study unduly influenced the pooled estimate (see Table 6 and Fig. 2).

\section{Discussion}

Historically, there has been little preventive effort to address antenatal depression in many countries, despite the associated risks for adverse pregnancy and birth outcomes $[7,65]$. It is possible that this may be due to limited conclusive information available about the disorder. 


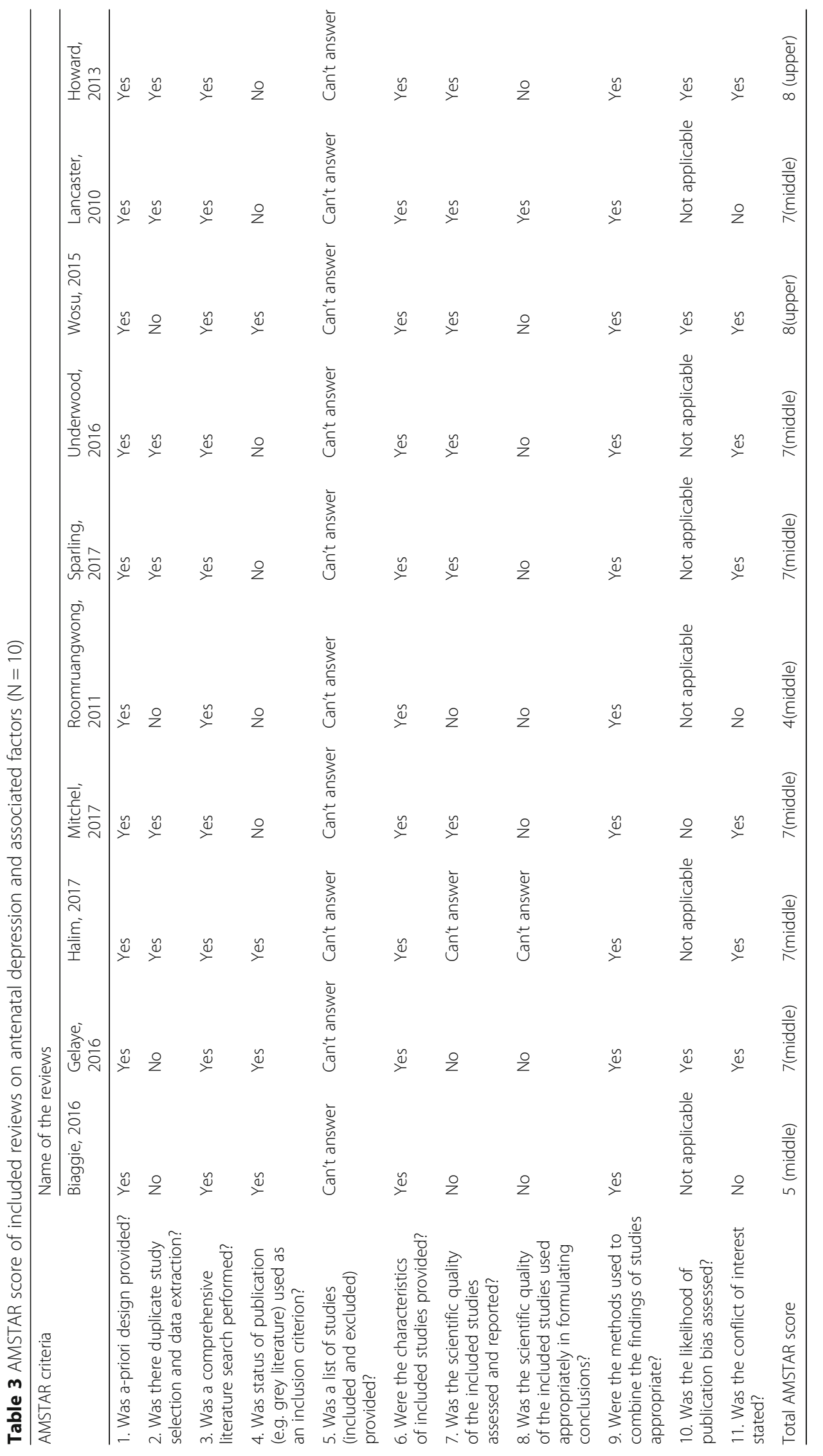




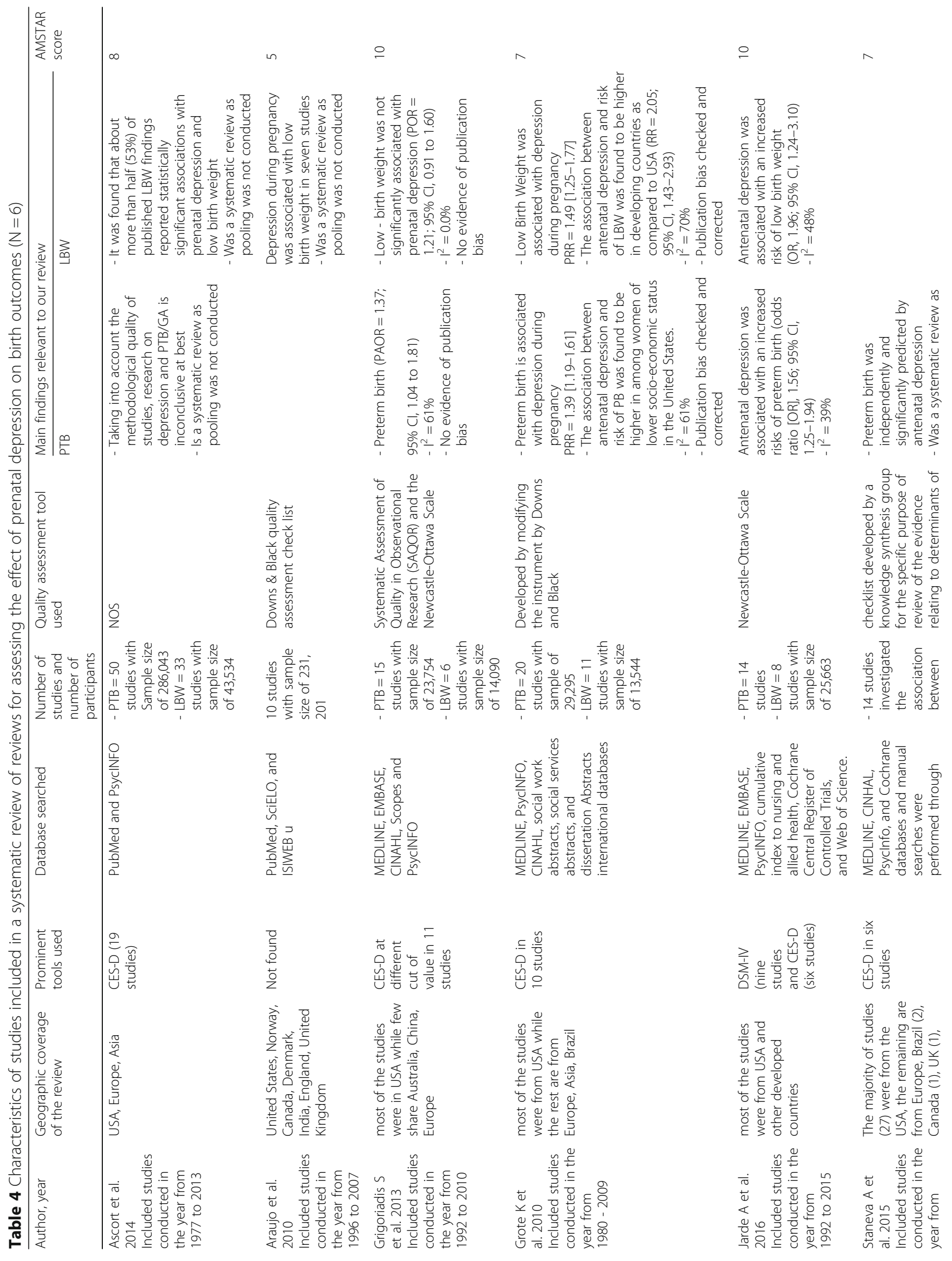




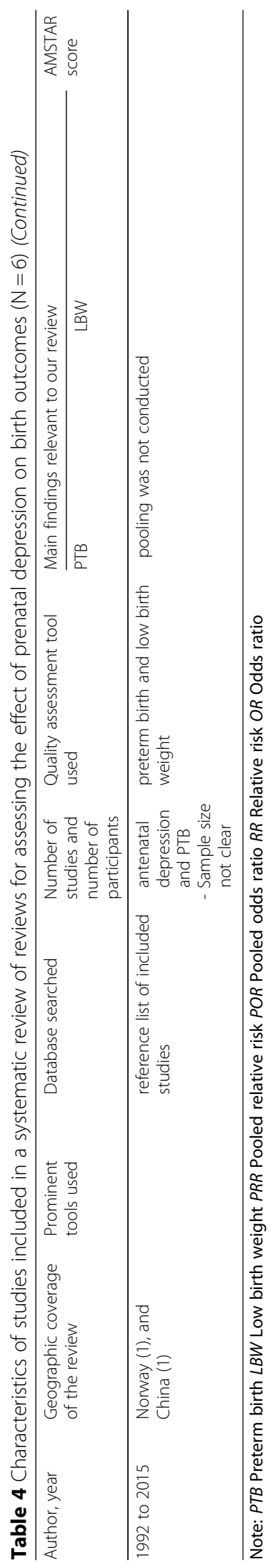


Table 5 Summary for reviews included in effect of antenatal depression on birth outcomes, a systematic review of reviews $(N=6)$

\begin{tabular}{|c|c|c|c|c|}
\hline Type of outcome & $\begin{array}{l}\text { Number of } \\
\text { primary studies }\end{array}$ & $\begin{array}{l}\text { Sample size } \\
\text { include }\end{array}$ & Estimates from review & Pooled estimates, $I^{2}$ \\
\hline \multirow[t]{3}{*}{ Low birth weight } & 6 & 14,090 & PAOR, $(1.21 ; 95 \% C l: 0.91,1.60)$ & \multirow{3}{*}{$\begin{array}{l}\text { PAOR }=1.49(95 \% \mathrm{Cl}: 1.32,1.68) \\
\mathrm{I}^{2}=0.0 \%(P=0.213) \\
\text { - No evidence of publication bias } \\
\text { - No influential study found }\end{array}$} \\
\hline & 11 & 13,544 & $\mathrm{PRR}=1.49(95 \% \mathrm{Cl}: 1.25,1.77)$ & \\
\hline & 8 & 25,663 & $\mathrm{PAOR}=1.96(95 \% \mathrm{Cl}: 1.24,3.10)$ & \\
\hline Total & 25 & 53,297 & & \\
\hline \multirow[t]{3}{*}{ Preterm birth } & 15 & 23,754 & PAOR, $(1.37 ; 95 \% C l: 1.04,1.81)$ & \multirow{3}{*}{$\begin{array}{l}\text { PAOR }=1.40(95 \% \mathrm{Cl}: 1.16,1.69) \\
I^{2}=35.2 \%(P=0.771) \\
\text { - No evidence of publication bias } \\
\text { - No influential study found }\end{array}$} \\
\hline & 20 & \multirow[t]{2}{*}{29,295} & $\mathrm{PRR}=1.39(95 \% \mathrm{Cl}: 1.19,1.61)$ & \\
\hline & 14 & & $\mathrm{PAOR}=1.56(95 \% \mathrm{Cl}: 1.25,1.94)$ & \\
\hline Total & 39 & 75,451 & & \\
\hline
\end{tabular}

Note: PAOR Pooled adjusted odds ratio PRR Pooled relative risk

We conducted this systematic review of reviews to comprehensively summarize the global burden of antenatal depression and its consequences on birth outcomes. We found antenatal depression prevalence ranged from 15 to $65 \%$ based on ten identified systematic reviews, themselves based on 306 primary studies. Antenatal depression was identified as a risk factor for low birth weight and preterm birth when estimates from six systematic reviews (based on 64 primary studies) were summarized.
Four systematic reviews reported a pooled prevalence of antenatal depression [6, 46, 54, 58], from which two were included studies from low and middle income countries $[46,54]$ while only one review included studies from high income countries [6]. A pooled antenatal depression prevalence of $17 \%$ was found in a review conducted in developed countries while a prevalence range of $15-65 \%$ was reported in a review conducted by including studies from low-and middle-income

Table 6 AMSTAR score of included reviews for effect of antenatal depression on adverse birth outcomes $(N=6)$

\begin{tabular}{|c|c|c|c|c|c|c|}
\hline \multirow[t]{2}{*}{ AMSTAR criteria } & \multicolumn{6}{|c|}{ Name of the reviews } \\
\hline & Accort, 2015 & Araujo, 2010 & Grigoriadis, 2013 & Grote, 2010 & Jarde, 2016 & Staneva, 2015 \\
\hline 1. Was a-priori design provided? & Yes & Yes & Yes & Yes & Yes & Yes \\
\hline $\begin{array}{l}\text { 2. Was there duplicate study selection } \\
\text { and data extraction? }\end{array}$ & Yes & No & Yes & Yes & Yes & Yes \\
\hline $\begin{array}{l}\text { 3. Was a comprehensive literature } \\
\text { search performed? }\end{array}$ & Yes & Yes & Yes & Yes & Yes & Yes \\
\hline $\begin{array}{l}\text { 4. Was status of publication } \\
\text { (e.g. grey literature) used as an } \\
\text { inclusion criterion? }\end{array}$ & No & No & Yes & No & Yes & No \\
\hline $\begin{array}{l}\text { 5. Was a list of studies } \\
\text { (included and excluded) provided? }\end{array}$ & Can't answer & Can't answer & Can't answer & Can't answer & Can't answer & Can't answer \\
\hline $\begin{array}{l}\text { 6. Were the characteristics of } \\
\text { included studies provided? }\end{array}$ & Yes & Yes & Yes & Yes & Yes & Yes \\
\hline $\begin{array}{l}\text { 7. Was the scientific quality of the } \\
\text { included studies assessed and } \\
\text { reported? }\end{array}$ & Yes & Yes & Yes & Yes & Yes & Yes \\
\hline $\begin{array}{l}\text { 8. Was the scientific quality } \\
\text { of the included studies used } \\
\text { appropriately in formulating } \\
\text { conclusions? }\end{array}$ & Yes & No & Yes & No & Yes & No \\
\hline $\begin{array}{l}\text { 9. Were the methods used to } \\
\text { combine the findings of studies } \\
\text { appropriate? }\end{array}$ & Yes & Yes & Yes & Yes & Yes & Yes \\
\hline $\begin{array}{l}\text { 10. Was the likelihood of } \\
\text { publication bias assessed? }\end{array}$ & Not applicable & Not applicable & Yes & Yes & Yes & Not applicable \\
\hline $\begin{array}{l}\text { 11. Was the conflict of } \\
\text { interest stated? }\end{array}$ & Yes & No & Yes & No & Yes & Yes \\
\hline Total AMSTAR score & 8 (upper) & 5(middle) & 10 (upper) & 7(middle) & 10(upper) & 7(upper) \\
\hline
\end{tabular}




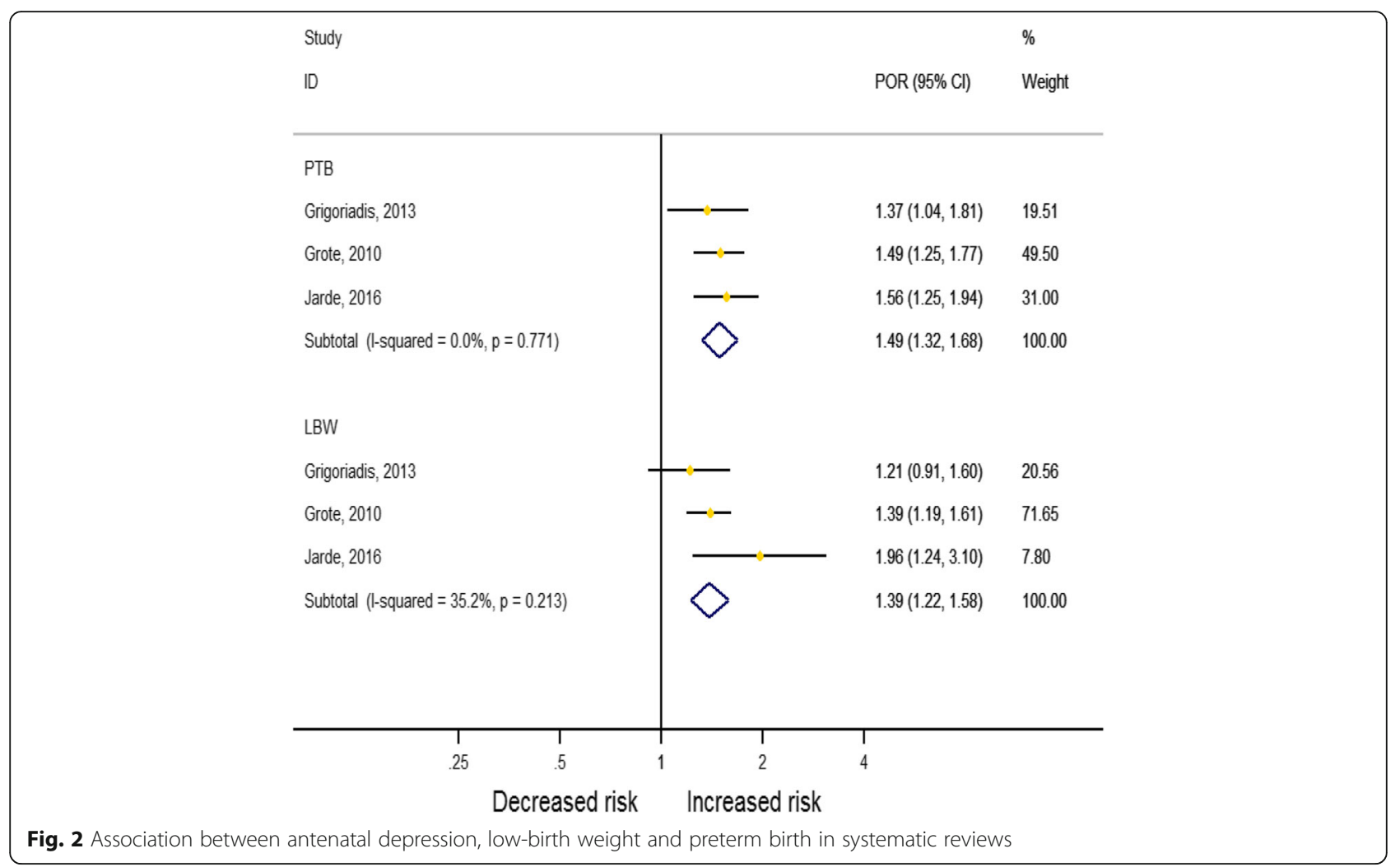

countries. All systematic reviews conducted by including primary studies from developed countries and low- and middle-income countries revealed a significantly high burden of the disorder, implying that it should be considered a major public health problem during pregnancy. Our finding supported that depression disorder was a significant cause of disease burden globally as also clearly indicated in the Global Burden of Disease studies [11, 66].

Depression is relatively common across the population but is known to be more prevalent in females relative to males [18, 67-70]. Risk for depression in females doubles during pregnancy [71], which is thought to be due to a mixture of hormonal changes and a range of psychosocial factors [72-75] that may continue to impact on mental health throughout the lifespan [74].

Given the primary caregiving role that women often have, antenatal depression may ultimately have significant implications for child development [76]. It has been proposed that maternal depression could have an intergenerational effect as female born to depressed mothers were two times at risk of having perinatal depression relative to those born to non-depressed mothers [77, 78]. In females whose mothers experienced depression, signs of depression have been noted at age $20(38 \%)$ and 35 years (65\%) [79], which might be explained by 'fetal programming' [80]. The negative impacts of maternal depression on child development have been identified as physical, behavioral, social, emotional and cognitive [81, 82]. Maternal depression may also result in poor intrauterine growth, miscarriage, and other adverse maternal and birth outcomes that could lead to increased infant morbidity and mortality [23]. Despite these impacts, to date, no routine maternal depression interventions have been implemented globally $[67,83,84]$.

Although six systematic reviews reported history of abuse or violence as a risk factor of antenatal depression $[56,58]$, from considering the information across a number of systematic reviews, our study is the first to identify a history of abuse or violence as the principal risk for antenatal depression. A number of experimental studies explain the biological mechanisms underlying the association between life time abuse and violence and later depression. The alteration of brain morphology and function $[85,86]$, hormonal fluctuations and high concentration of corticotrophin releasing hormone, and cortisol production from hypothalamic adrenal pituitary were associated with exposure to early life adversity [87, 88]. Previous studies have observed inflammatory and epigenetic pathways in people with depression symptoms $[89,90]$ and past memories of being abused and violated may increase risk of later depression [91, 92].

We found that reduced or absent social or partner support was the second most replicable risk factor for antenatal depression. Social and partner support during pregnancy is highly important as it can play a buffering role and enhance 
coping ability and emotional stability [93, 94]. In contrast, lack of social support has been noted to enhance feelings of worthlessness and hopelessness [95].

Unplanned pregnancy and history of obstetric complication were also identified as important predictors of antenatal depression. Perceptions of increased economic burden and reduced ability to cope potential societal stigma may increase the risk of developing stress or depression $[58,96]$. Adverse pregnancy and birth outcomes are often traumatic events, and a history of such complications may increase levels of stress during later pregnancy $[19,48,53]$.

Socio-economic and behavioral determinants such as financial difficulties (reported in three reviews of 32 primary studies), lower educational status (reported in two reviews of 22 primary studies) and health compromising behaviors (reported in one review of 29 primary studies) were also found to increase the odds of depression during pregnancy.

We confirmed that antenatal depression increased the risk of preterm birth and low birth weight. The causal mechanism between antenatal depression and adverse birth outcomes has been well established and could be explained both genetically and socio-environmentally. Hormonal dysregulation, antenatal depression and/or chronic stress lead to changes in hypothalamic pituitary adrenal axis (HPA) function. This results in stimulation of high cortisol production and release that can restrict flow of nutrients and oxygen to the fetus [97-100]. Antenatal depression may also affect maternal immune system function via glucocorticoid hormone imbalance that may increase susceptibility to various microbial infections [101-104] and poor fetal growth. In relation to socio-environmental factors, antenatal depression may reduce capacity to access maternal health services, while potentially increasing reliance on risk behaviors such as poor nutrition (under [105-108] or over nutrition) [109-111].

To our knowledge, this is the first systematic review of reviews examining antenatal depression and adverse birth outcomes published to date. Using a systematic approach to systematically review 16 high quality reviews, which collectively reviewed over 300 primary studies, has now provided a comprehensive compilation of relevant evidence on which to base effective health policy.

It is important, however, to consider some of the limitations of our study that may have affected our results. Although the use of validated screening tools among the primary sources reviewed by the studies included in our review form part of our quality assessment, the use of different validated depression screening tools with different cutoff values may have introduced some heterogeneity, as would the use of different study design among primary studies. Although we closely scrutinized the primary studies for duplication, there remains the potential for versions reporting the same primary study to have been included in multiple reviews, which is a known limitation of the systematic review of reviews method. Given the majority of included reviews were conducted in higher income countries, reviews from low income countries were therefore underrepresented.

\section{Conclusions}

Our systematic review of reviews confirmed that there is a high prevalence of antenatal depression in the world and a particularly high prevalence in low income countries relative to high income countries. Whilst the association between antenatal depression and adverse birth outcomes appeared modest, its absolute impact would be significant in lower-income countries with a high prevalence of antenatal depression and poor access to quality mental health services. Antenatal mental health screening has been established in higher income countries but low- and middle-income countries, who shoulder a higher burden of antenatal depression, lags far behind in implementing any intervention and management measures. Based on our findings, it is important to increase the focus on antenatal depression screening in order to address the largely avoidable adverse impacts on maternal and infant outcomes.

\section{Abbreviations \\ AMSTAR: Assessment of Multiple Systematic Reviews; AND: Antenatal Depression; CED-S: Center for Epidemiological Depression Scale; DSM- IV: Diagnostic and Statistical Manual of Mental Disorders; EPDS: Edinburgh Postnatal Depression Scale; LMP: Last Menstrual Cycle; MDD: Major Depressive Episode; WHO: World Health Organization}

\section{Acknowledgements \\ Note Applicable.}

\section{Authors' contributions}

AFD, LM, ERM, TAB: conceived the design and develop the search strategy; AFD: searched, screened, and appraised the studies and extract the data: AFD analyzed the data and drafted the manuscript. LM, TAB, ERM critically reviewed and revised the manuscript and all authors read and approved the final manuscript for publication.

Funding

None to declare.

Availability of data and materials

All data generated or analyzed during this review are included in this manuscript.

Ethics approval and consent to participate

Not Applicable.

Consent for publication

Not applicable.

\section{Competing interests}

The authors declare no competing interest. Abel Fekadu Dadi is member of academic editor (Associate editor) of BMC Public Health. 


\section{Author details}

${ }^{1}$ College of Medicine and Public Health, Flinders University, Health Sciences Building, Sturt Road, Bedford Park, Adelaide, SA 5001, Australia. ${ }^{2}$ Department of Epidemiology and Biostatistics, Institute of Public Health, College of Medicine and Health Sciences, University of Gondar, Gondar, Ethiopia. ${ }^{3}$ Department of Health promotion and Behavioral sciences, Institute of Public Health, College of Medicine and Health Sciences, University of Gondar, Gondar, Ethiopia.

Received: 27 June 2019 Accepted: 28 January 2020

Published online: 04 February 2020

\section{References}

1. Vahia VN. Diagnostic and statistical manual of mental disorders 5: a quick glance. Indian J Psychiatry. 2013;55(3):220-3.

2. Marcus SM, Heringhausen JE. Depression in childbearing women: when depression complicates pregnancy. Primary Care. 2009;36(1):151-ix.

3. Vigod SN, Wilson CA, Howard LM. Depression in pregnancy. Bmj. 2016;352:i1547.

4. Goodman SH. Depression in mothers. Annu Rev Clin Psychol. 2007;3:107-35.

5. Woolhouse H, Gartland D, Mensah F, Brown SJ. Maternal depression from early pregnancy to 4 years postpartum in a prospective pregnancy cohort study: implications for primary health care. Bjog. 2015;122(3):312-21.

6. Underwood L, Waldie K, D'Souza S, Peterson ER, Morton S. A review of longitudinal studies on antenatal and postnatal depression. Arch Womens Ment Health. 2016;19(5):711-20.

7. Heron J, O'Connor TG, Evans J, Golding J, Glover V. The course of anxiety and depression through pregnancy and the postpartum in a community sample. J Affect Disord. 2004;80(1):65-73.

8. Kingston D, Kehler H, Austin MP, Mughal MK, Wajid A, Vermeyden L, et al. Trajectories of maternal depressive symptoms during pregnancy and the first 12 months postpartum and child externalizing and internalizing behavior at three years. PLoS One. 2018;13(4):e0195365.

9. Metrics $\mathrm{IfH}$, Evaluation. GBD compare. $\mathrm{IHME}$, University of Washington Seattle, WA; 2015.

10. Ferrari AJ, Charlson FJ, Norman RE, Patten SB, Freedman G, Murray CJL, et al. Burden of depressive disorders by country, sex, age, and year: findings from the global burden of disease study 2010. PLoS Med. 2013;10(11):e1001547.

11. Global Burden of Disease Studies. Global, regional, and national incidence, prevalence, and years lived with disability for 354 diseases and injuries for 195 countries and territories, 1990-2017: a systematic analysis for the Global Burden of Disease Study 2017. Lancet. 2018;392(10159).

12. Bauer A, Parsonage $M$, Knapp M, lemmi V, Adelaja B. Costs of perinatal mental health problems. 2014.

13. Shen H, Magnusson C, Rai D, Lundberg M, Le-Scherban F, Dalman C, et al. Associations of parental depression with child school performance at age 16 years in Sweden. JAMA Psychiatry. 2016;73(3):239-46.

14. Araujo DM, Vilarim MM, Sabroza AR, Nardi AE. Depression during pregnancy and low birth weight: a systematic literature review. Cad Saude Publica. 2010;26(2):219-27.

15. Grote NK, Bridge JA, Gavin AR, Melville JL, lyengar S, Katon WJ. A metaanalysis of depression during pregnancy and the risk of preterm birth, low birth weight, and intrauterine growth restriction. Arch Gen Psychiatry. 2010; 67(10):1012-24.

16. Grigoriadis S, VonderPorten EH, Mamisashvili L, Tomlinson G, Dennis CL, Koren $\mathrm{G}$, et al. The impact of maternal depression during pregnancy on perinatal outcomes: a systematic review and meta-analysis. J Clin Psychiatry. 2013;74(4):e321-e41.

17. Accortt EE, Cheadle AC, Dunkel SC. Prenatal depression and adverse birth outcomes: an updated systematic review. Matern Child Health J. 2015;19(6):1306-37.

18. Marcus SM. Depression during pregnancy: rates, risks and consequences-Motherisk update 2008. Can J Clin Pharmacol. 2009;16(1):e15-22.

19. Byrn MA, Penckofer S. Antenatal depression and gestational diabetes: a review of maternal and fetal outcomes. Nurs Womens Health. 2013; 17(1):22-33.

20. Hoirisch-Clapauch S, Brenner B, Nardi AE. Adverse obstetric and neonatal outcomes in women with mental disorders. Thromb Res. 2015; 135(Suppl 1):S60-3.

21. Gentile S. Untreated depression during pregnancy: short- and long-term effects in offspring. A systematic review. Neuroscience. 2017;342:154-66.
22. Jacques N, de Mola CL, Joseph G, Mesenburg MA, da Silveira MF. Prenatal and postnatal maternal depression and infant hospitalization and mortality in the first year of life: a systematic review and meta-analysis. J Affect Disord. 2019;243:201-8.

23. Alder J, Fink N, Bitzer J, Hosli I, Holzgreve W. Depression and anxiety during pregnancy: a risk factor for obstetric, fetal and neonatal outcome? A critical review of the literature. J Matern Fetal Neonatal Med. 2007;20(3):189-209.

24. Davalos DB, Yadon CA, Tregellas HC. Untreated prenatal maternal depression and the potential risks to offspring: a review. Arch Womens Ment Health. 2012;15(1):1-14.

25. Dunkel Schetter C, Tanner L. Anxiety, depression and stress in pregnancy: implications for mothers, children, research, and practice. Curr Opin Psychiatry. 2012;25(2):141-8.

26. Szegda K, Markenson G, Bertone-Johnson ER, Chasan-Taber L. Depression during pregnancy: a risk factor for adverse neonatal outcomes? A critical review of the literature. J Matern Fetal Neonatal Med. 2014;27(9):960-7.

27. Becker M, Weinberger T, Chandy A, Schmukler S. Depression during pregnancy and postpartum. Curr Psychiatry Rep. 2016;18(3):32.

28. Downey G, Coyne JC. Children of depressed parents: an integrative review. Psychol Bull. 1990;108(1):50.

29. Goodman SH, Gotlib IH. Risk for psychopathology in the children of depressed mothers: a developmental model for understanding mechanisms of transmission. Psychol Rev. 1999;106(3):458.

30. Griggs D, Stafford-Smith M, Gaffney O, Rockström J, Öhman MC, Shyamsundar P, et al. Policy: sustainable development goals for people and planet. Nature. 2013;495(7441):305.

31. Organization WH. Health in 2015: from MDGs, millennium development goals to SDGs, sustainable development goals. 2015.

32. Frey HA, Klebanoff MA. The epidemiology, etiology, and costs of preterm birth. Semin Fetal Neonatal Med. 2016;21(2):68-73.

33. Simmons LE, Rubens CE, Darmstadt GL, Gravett MG. Preventing preterm birth and neonatal mortality: exploring the epidemiology, causes, and interventions. Semin Perinatol. 2010;34(6):408-15.

34. Purisch SE, Gyamfi-Bannerman C. Epidemiology of preterm birth. Semin Perinatol. 2017;41(7):387-91.

35. Blencowe $H$, Cousens $S$, Oestergaard MZ, Chou D, Moller A-B, Narwal R, et al. National, regional, and worldwide estimates of preterm birth rates in the year 2010 with time trends since 1990 for selected countries: a systematic analysis and implications. Lancet. 2012;379(9832):2162-72.

36. Blencowe $H$, Cousens S, Chou D, Oestergaard M, Say L, Moller A-B, et al. Born too soon: the global epidemiology of 15 million preterm births. Reprod Health. 2013;10(1):S2.

37. Smith V, Devane D, Begley CM, Clarke M. Methodology in conducting a systematic review of systematic reviews of healthcare interventions. BMC Med Res Methodol. 2011;11(1):15.

38. Lau R, Stevenson F, Ong BN, Dziedzic K, Treweek S, Eldridge S, et al. Achieving change in primary care--causes of the evidence to practice gap: systematic reviews of reviews. Implementation Sci. 2016;11:40.

39. Langell JTIJoHM. Evidence-based medicine: A data-driven approach to lean healthcare operations. 2019:1-4.

40. Hasanpoor E, Hallajzadeh J, Siraneh Y, Hasanzadeh E, Haghgoshayie E. Using the methodology of systematic review of reviews for evidence-based medicine. Ethiop J Health Sci. 2019;29(6):775-8.

41. Aromataris E, Fernandez R, Godfrey CM, Holly C, Khalil H, Tungpunkom P. Summarizing systematic reviews: methodological development, conduct and reporting of an umbrella review approach. 2015;13(3):132-40.

42. Brummelte $S$, Galea LA. Depression during pregnancy and postpartum: contribution of stress and ovarian hormones. Prog Neuro-Psychopharmacol Biol Psychiatry. 2010;34(5):766-76.

43. Roomruangwong C, Epperson CN. Perinatal depression in Asian women: prevalence, associated factors, and cultural aspects. 2011;5(2):179.

44. Woody CA, Ferrari AJ, Siskind DJ, Whiteford HA, Harris MG. A systematic review and meta-regression of the prevalence and incidence of perinatal depression. J Affect Disord. 2017;219:86-92.

45. Garcia ER, Yim IS. A systematic review of concepts related to women's empowerment in the perinatal period and their associations with perinatal depressive symptoms and premature birth. BMC Pregnancy Childbirth. 2017:17(Suppl 2):347.

46. Gelaye B, Rondon MB, Araya R, Williams MA. Epidemiology of maternal depression, risk factors, and child outcomes in low-income and middleincome countries. Lancet Psychiatry. 2016;3(10):973-82. 
47. Field T, Diego M, Hernandez-Reif M. Prenatal depression effects and interventions: a review. Infant Behav Dev. 2010;33(4):409-18.

48. Molyneaux E, Poston L, Ashurst-Williams S, Howard LM. Obesity and mental disorders during pregnancy and postpartum: a systematic review and metaanalysis. Obstet Gynecol. 2014;123(4):857-67.

49. Mukherjee S, Trepka MJ, Pierre-Victor D, Bahelah R, Avent T. Racial/ethnic disparities in antenatal depression in the United States: a systematic review. Matern Child Health J. 2016;20(9):1780-97.

50. Silveira ML, Ertel KA, Dole N, Chasan-Taber L. The role of body image in prenatal and postpartum depression: a critical review of the literature. Arch Womens Ment Health. 2015;18(3):409-21.

51. Gracka-Tomaszewska M. Psychological factors during pregnancy correlated with infant low birth weigh. Pediatr Endocrinol Diabetes Metab. 2010;16(3):216-9.

52. Chatillon O, Even C. Antepartum depression: prevalence, diagnosis and treatment. Encephale. 2010;36(6):443-51.

53. Biaggi A, Conroy S, Pawlby S, Pariante CM. Identifying the women at risk of antenatal anxiety and depression: a systematic review. J Affect Disord. 2016;191:62-77.

54. Halim N, Beard J, Mesic A, Patel A, Henderson D, Hibberd P. Intimate partner violence during pregnancy and perinatal mental disorders in low and lower middle income countries: A systematic review of literature, 19902017. Clin Psychol Rev. 2017.

55. Howard LM, Oram S, Galley H, Trevillion K, Feder G. Domestic violence and perinatal mental disorders: a systematic review and meta-analysis. PLoS Med. 2013;10(5):e1001452.

56. Lancaster CA, Gold K, Flynn HA, Yoo H, Marcus SM, Davis MM. Risk factors for depressive symptoms during pregnancy: a systematic review. Am J Obstet Gynecol. 2010;202(1):5-14.

57. Mitchell-Jones N, Gallos I, Farren J, Tobias A, Bottomley C, Bourne T. Psychological morbidity associated with hyperemesis gravidarum: a systematic review and meta-analysis. Bjog. 2017;124(1):20-30.

58. Roomruangwong C, Epperson CN. Perinatal depression in Asian women: prevalence, associated factors, and cultural aspects. Asian Biomed. 2011;5(2):179-93.

59. Sparling TM, Henschke N, Nesbitt RC, Gabrysch S. The role of diet and nutritional supplementation in perinatal depression: a systematic review. Matern Child Nutr. 2017;13(1).

60. Wosu AC, Gelaye B, Williams MA. History of childhood sexual abuse and risk of prenatal and postpartum depression or depressive symptoms: an epidemiologic review. Arch Womens Ment Health. 2015;18(5):659-71.

61. Jarde A, Morais M, Kingston D, Giallo R, MacQueen GM, Giglia L, et al. Neonatal outcomes in women with untreated antenatal depression compared with women without depression: a systematic review and metaanalysis. JAMA Psychiatry. 2016;73(8):826-37.

62. Staneva A, Bogossian F, Pritchard M, Wittkowski A. The effects of maternal depression, anxiety, and perceived stress during pregnancy on preterm birth: a systematic review. Women Birth. 2015;28(3):179-93.

63. Cox JL, Holden JM, Sagovsky R. Detection of postnatal depression: development of the 10-item Edinburgh postnatal depression scale. $\mathrm{Br}$ J Psychiatry. 1987;150(6):782-6.

64. Radloff LS. The CES-D scale: a self-report depression scale for research in the general population. Appl Psychol Meas. 1977;1(3):385-401.

65. Norhayati MN, Hazlina NH, Asrenee AR, Emilin WM. Magnitude and risk factors for postpartum symptoms: a literature review. J Affect Disord. 2015;175:34-52.

66. Global, regional, and national incidence, prevalence, and years lived with disability for 328 diseases and injuries for 195 countries, 1990-2016: a systematic analysis for the Global Burden of Disease Study 2016. Lancet. 2017;390(10100):1211-59.

67. Benbow SM. Psychiatric Illness in Women: Emerging Treatment and Research. Edited by F. Lewis-Hall, T. S. Williams, J. A. Panetta and J. M. Herrera. American Psychiatric Publishing Inc., Washington, 2002. Pages: 658. International Journal of Geriatric Psychiatry. 2003;18(11):1065-.

68. Grigoriadis S, Robinson GE. Gender issues in depression. Ann Clin Psychiatry. 2007;19(4):247-55.

69. Bina R. The impact of cultural factors upon postpartum depression: a literature review. Health Care Women Int. 2008;29(6):568-92.

70. Varkukla M, Viguera AC, Gonsalves L. Depression and pregnancy. Compr Ther. 2009;35(1):44-9.

71. Kessler RC, Berglund P, Demler O, Jin R, Koretz D, Merikangas KR, et al. The epidemiology of major depressive disorder: results from the National Comorbidity Survey Replication (NCS-R). Jama. 2003;289(23):3095-105.
72. Bromet E, Andrade LH, Hwang I, Sampson NA, Alonso J, de Girolamo G, et al. Cross-national epidemiology of DSM-IV major depressive episode. BMC Med. 2011;9:90.

73. Goldstein JM, Holsen L, Handa R, Tobet S. Fetal hormonal programming of sex differences in depression: linking women's mental health with sex differences in the brain across the lifespan. Front Neurosci. 2014;8:247

74. Soares CN, Zitek B. Reproductive hormone sensitivity and risk for depression across the female life cycle: a continuum of vulnerability? JPN. 2008;33(4):331-43.

75. Sundstrom Poromaa I, Comasco E, Georgakis MK, Skalkidou A. Sex differences in depression during pregnancy and the postpartum period. J Neurosci Res. 2017;95(1-2):719-30.

76. Anderson J. The impact of family structure on the health of children: effects of divorce. Linacre Q. 2014;81(4):378-87.

77. Carbone DL, Handa RJ. Sex and stress hormone influences on the expression and activity of brain-derived neurotrophic factor. Neuroscience. 2013;239:295-303.

78. Seney ML, Ekong Kl, Ding Y, Tseng GC, Sibille E. Sex chromosome complement regulates expression of mood-related genes. Biol Sex Differ. 2013;4(1):20.

79. Havinga PJ, Boschloo L, Hartman CA, Schoevers RA. Paternal and maternal depression and offspring risk: additive effects or worse? Lancet Psychiatry. 2018;5(2):107-8.

80. Herba CM, Glover V, Ramchandani PG, Rondon MB. Maternal depression and mental health in early childhood: an examination of underlying mechanisms in low-income and middle-income countries. Lancet Psychiatry. 2016;3(10):983-92.

81. Glover V. Prenatal stress and its effects on the fetus and the child: possible underlying biological mechanisms. Adv Neurobiol. 2015;10:269-83.

82. Glover V. Maternal depression, anxiety and stress during pregnancy and child outcome; what needs to be done. Best Pract Res Clin Obstet Gynaecol. 2014;28(1):25-35.

83. Alderdice F, McNeill J, Lynn F. A systematic review of systematic reviews of interventions to improve maternal mental health and well-being. Midwifery. 2013;29(4):389-99.

84. Brandon AR, Crowley SK, Gordon JL, Girdler SS. Nonpharmacologic treatments for depression related to reproductive events. Curr Psychiatry Rep. 2014;16(12):526.

85. Davidson RJ, McEwen BS. Social influences on neuroplasticity: stress and interventions to promote well-being. Nat Neurosci. 2012;15(5):689-95.

86. Oberman L, Pascual-Leone A. Changes in plasticity across the lifespan: cause of disease and target for intervention. Prog Brain Res. 2013;207:91-120.

87. Feng X, Wang L, Yang S, Qin D, Wang J, Li C, et al. Maternal separation produces lasting changes in cortisol and behavior in rhesus monkeys. Proc Natl Acad Sci U S A. 2011;108(34):14312-7.

88. Dettmer AM, Novak MA, Suomi SJ, Meyer JS. Physiological and behavioral adaptation to relocation stress in differentially reared rhesus monkeys: hair cortisol as a biomarker for anxiety-related responses. Psychoneuroendocrinology. 2012;37(2):191-9.

89. Drury SS, Mabile E, Brett ZH, Esteves K, Jones E, Shirtcliff EA, et al. The association of telomere length with family violence and disruption. Pediatrics. 2014;134(1):e128-37.

90. Karabatsiakis A, Kolassa IT, Kolassa S, Rudolph KL, Dietrich DE. Telomere shortening in leukocyte subpopulations in depression. BMC Psychiatry. 2014;14:192.

91. Leeners B, Stiller R, Block E, Görres G, Rath W, Tschudin S. Prenatal care in adult women exposed to childhood sexual abuse. J Perinat Med. 2013:365.

92. Montgomery E, Pope C, Rogers J. The re-enactment of childhood sexual abuse in maternity care: a qualitative study. BMC Pregnancy Childbirth. 2015;15:194.

93. Bilszta JL, Tang M, Meyer D, Milgrom J, Ericksen J, Buist AE. Single motherhood versus poor partner relationship: outcomes for antenatal mental health. Aust N Z J Psychiatry. 2008;42(1):56-65.

94. Marchesi C, Bertoni S, Maggini C. Major and minor depression in pregnancy. Obstet Gynecol. 2009;113(6):1292-8.

95. Liabsuetrakul T, Vittayanont A, Pitanupong J. Clinical applications of anxiety, social support, stressors, and self-esteem measured during pregnancy and postpartum for screening postpartum depression in Thai women. J Obstet Gynaecol Res. 2007;33(3):333-40.

96. Recto P, Champion JD. Psychosocial risk factors for perinatal depression among female adolescents: a systematic review. Issues Ment Health Nurs. 2017;38(8):633-42. 
97. Sarkar P, Bergman K, O'Connor TG, Glover V. Maternal antenatal anxiety and amniotic fluid cortisol and testosterone: possible implications for foetal programming. J Neuroendocrinol. 2008;20(4):489-96.

98. Van den Bergh BR, Mulder EJ, Mennes M, Glover V. Antenatal maternal anxiety and stress and the neurobehavioural development of the fetus and child: links and possible mechanisms. A review Neurosci Biobehav Rev. 2005;29(2):237-58.

99. O'Donnell K, O'Connor TG, Glover V. Prenatal stress and neurodevelopment of the child: focus on the HPA axis and role of the placenta. Dev Neurosci. 2009;31(4):285-92.

100. Kumar S, Gordon GH, Abbott DH, Mishra JS. Androgens in maternal vascular and placental function: implications for preeclampsia pathogenesis. Reproduction (Cambridge, England). 2018;156(5):R155-r67.

101. Reynolds RM. Glucocorticoid excess and the developmental origins of disease: two decades of testing the hypothesis--2012 Curt Richter award winner. Psychoneuroendocrinology. 2013;38(1):1-11.

102. Orr ST, Blazer DG, James SA, Reiter JP. Depressive symptoms and indicators of maternal health status during pregnancy. J Women's Health (2002). 2007;16(4):535-42.

103. Marcus SM, Heringhausen JE. Depression in childbearing women: when depression complicates pregnancy. Prim Care. 2009;36(1):151-65 ix.

104. Couret D, Prunier A, Mounier AM, Thomas F, Oswald IP, Merlot E. Comparative effects of a prenatal stress occurring during early or late gestation on pig immune response. Physiol Behav. 2009;98(4):498-504

105. Roth CK, Satran LA, Smith SM. Marijuana Use in Pregnancy. Nurs Women's Health. 2015;19(5):431-7.

106. Jacobson SW, Bihun JT, Chiodo LM. Effects of prenatal alcohol and cocaine exposure on infant cortisol levels. Dev Psychopathol. 1999;11(2):195-208.

107. Bingham RJ. Latest evidence on alcohol and pregnancy. Nurs Women's Health. 2015;19(4):338-44.

108. Dale MTG, Bakketeig LS, Magnus P. Alcohol consumption among firsttime mothers and the risk of preterm birth: a cohort study. Ann Epidemiol. 2016;26(4):275-82.

109. Pratt BM, Woolfenden SR. Interventions for preventing eating disorders in children and adolescents. Cochrane Database Syst Rev. 2002;(2):Cd002891.

110. Stavrou S, Nicolaides NC, Papageorgiou I, Papadopoulou P, Terzioglou E, Chrousos GP, et al. The effectiveness of a stress-management intervention program in the management of overweight and obesity in childhood and adolescence. J Mol Biochem. 2016;5(2):63-70.

111. van Dammen L, Wekker V, de Rooij SR, Groen H, Hoek A, Roseboom TJ. A systematic review and meta-analysis of lifestyle interventions in women of reproductive age with overweight or obesity: the effects on symptoms of depression and anxiety. Obes Rev. 2018;19(12):1679-87.

\section{Publisher's Note}

Springer Nature remains neutral with regard to jurisdictional claims in published maps and institutional affiliations.

Ready to submit your research? Choose BMC and benefit from:

- fast, convenient online submission

- thorough peer review by experienced researchers in your field

- rapid publication on acceptance

- support for research data, including large and complex data types

- gold Open Access which fosters wider collaboration and increased citations

- maximum visibility for your research: over $100 \mathrm{M}$ website views per year

At BMC, research is always in progress.

Learn more biomedcentral.com/submissions 